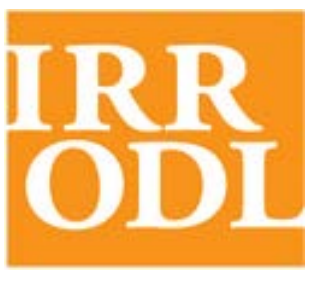

International

Review of

Research in Open

and Distance

Learning

Vol. 12.1

January -2011

\section{A Dynamic Community of Discovery: Planning, Learning, and Change}

\author{
Michelle Gordon, Martha Ireland, and Mina Wong \\ Ryerson University, Canada
}

\begin{abstract}
Ryerson University's Prior Learning and Competency Evaluation and Documentation (PLACED) program is funded by the Government of Ontario to engage internationally educated professionals (IEPs), employers, and regulatory/occupational bodies in the use of competency-based practices. In 2008, the authors created a self-assessment tool for IEPs that would build a portfolio reflecting an individual's knowledge and skills while introducing him or her to aspects of the Canadian workplace and labour market. The authors felt that this tool would be useful to assist IEPs in considering their career options and wanted to create an online workshop that would provide flexibility to users whose priorities were most likely work and family obligations. This short project description will capture a) why the self-assessment tool was developed; (b) how we fostered participants' self-efficacy; c) how we used Blackboard; (d) what the participants gained from the workshop; and (e) how the workshop has evolved based on facilitators' observations, participants' feedback, and an external organization's request for customizing the workshop. In working together to design the online workshop, IEPs' Self-Assessment and Planning, we focused on two main concepts: self-assessment and career planning. With that in mind, we set out in the workshop to bolster self-discovery, self-efficacy, individualized research skills, action planning, and ongoing professional development. The learning platform was Blackboard, which is used across Ryerson University in both classroom and online learning.
\end{abstract}

Keywords: Online learning; internationally educated professionals; adult education 


\section{Development of the Learning Tool}

Since the workshop was designed to enhance the career success of IEPs new to Canada, the need for flexible delivery and access to using online learning was as important as the participants' demonstration of competencies in online research skills and navigating virtual environments. These two skills are becoming integral to success in the Canadian workplace, so we incorporated them as an added benefit of learning.

Our first workshop was offered in 2009 over 10 weeks and had 21 participants. A 10-week workshop proved to be too long. The content was extensively reworked by Gordon and Wong and thereafter offered in a six-week format, one module per week. Each module included an ongoing storyline with two immigrant professionals exploring their options in Canada, reflecting some of the experiences of our workshop's target audience. The six-week workshop is offered every term (three times a year) in an online format.

\section{Design Background and Core Learning Benefits}

In this collaborative workshop, IEPs were invited to rediscover and transform themselves through confronting change, increasing self-direction, building self-efficacy, and achieving selfempowerment. The adult education principles that supported this journey include lifelong learning (Livingstone 2002), motivation (Wlodkowski \& Ginsberg 2003; Wlodkowski 2008), social learning (Bandura 1994), Dale’s experiential learning (Lemke 2008; Pastore 2003), transformation (Mezirow 1994), Erikson's adult development (Hoare 2005), and adult multiple intelligence (Gardner \& Moran 2006). Using a narrative method of inquiry (Bruner 1991) for adult learners to share individual and collective stories, we wove their discoveries and experiences into the learning space.

Offering the workshop online has many benefits for students; for instance, they have access to the resources whenever they choose without incurring the costs of travel to the campus. Beard and Harper (2004) conclude that despite students' concerns about the lack of face-to-face interaction with faculty and fellow students, they were quite supportive of and receptive to online instruction.

Within a safe community of nurturing facilitation and peer collaboration, the participants connected with each other and identified potential barriers. They also discovered intrinsic values of lifelong learning that could unfold opportunities in life, work, and further education. Moreover, IEPs made individual action plans and built portfolios to highlight their prior learning, marketable knowledge, and transferrable skills, such as teamwork.

\section{Facilitator Findings}

Workshop co-facilitators for the first two offerings, Michelle Gordon and Mina Wong, recognized that the portfolio helped individuals to see an accumulation of their work that provided comparative contexts from which to identify gaps in professional and academic prior 
learning, which often aided individuals in determining whether they needed to upgrade their skills. Considered a worthwhile process for documenting performance, the process of portfolio development also fostered professional growth and facilitated reflective thinking. The selfreflection inherent in the portfolio process encouraged individuals to frame their skills in fuller terms, to further identify the transferable skills they already possessed, and to become aware of other competencies needed for building career goals (Michelson 2004). This finding supports Dietz (1995), who considered the portfolio "an envelope of the mind," comprised of ongoing assessments with purposeful collections that examine achievement, effort, improvement, and processes such as selection, comparing, sharing, self-evaluation, and goal setting.

The workshop was piloted at no cost to students. When subsequent offerings of the workshop had a tuition fee of CDN\$50.00, Gordon and Ireland noted that the fee posed a barrier to enrollment. In the large city of Toronto, where there are many agencies and other educational bodies funded to offer programming that is similar, although generally shorter in length with varying content and not online, it appears that potential students are unsure about the advantages of enrolling in our workshop.

PLACED is struggling with how to reach out to the general IEP population. We foresee that offering our workshop in partnership with employers may be one way to attract IEPs.

\section{Conclusion}

In summary, we observed how the online learning space of a collaborative workshop can ignite discovery and transformation for IEPs. Rather than trying to navigate their way through the maze of different employment options, workplace participants could now develop strategies to enhance their career search. The workshop enabled them to assess their skills, to learn the importance of networking, and to develop action plans. The online forum allowed them to share their stories and to motivate each other. Based on the professional portfolio created through the workshop's activities, it was clear that learners gained Canadian experience in career research and career planning.

Our experience with the health sector has made it possible for us to enter into discussions with a large health care facility in Toronto and to offer a version of this workshop to its internationally educated employees as professional development. Customizing this workshop to feature the interprofessional and client-care focus of this particular organization is our next step. We will also pursue offering further workshops that are adapted to reflect the unique cultural environments of other sectors. 


\section{References}

Bandura, A. (1994). Self-efficacy. In V. S. Ramachaudran (Ed.), Encyclopedia of human behavior, 4, 71-81. New York: Academic Press.

Beard, L A., \& Harper, C. (2004). Student perceptions of online versus campus instruction. Education, 122(4), 658-664.

Bruner, J. (1991). The narrative construction of reality. Critical Inquiry, 18(1), 1.

Dietz, M. E. (1995). Using portfolios as a framework for professional development. Journal of Staff Development, 16(2), 40-43.

Gardner, H., \& Moran, S. (2006). The science of multiple intelligences theory: A response to Lynn Waterhouse. Educational Psychologist, 41(4), 227-232.

Hoare, C. H. (2005). Erikson's general and adult developmental revisions of Freudian thought: “Outward, forward, upward.” Journal of Adult Development, 12(1), 19-31.

Lemke, C. (2008). Cone of learning (Edgar Dale). Multimodal learning through media: What the research Says. San Jose, CA: Cisco Systems, Inc.

Livingstone, D. (2002). Working and learning in the information age: A Canadian profile. Ottawa: Canadian Policy Research Networks.

Mezirow, J. (1994). Understanding transformation theory. Adult Education Quarterly, 44(4), 222-232.

Michelson, E., \& Mandell, A. (2004). Portfolio development and the assessment of prior learning. Sterling, Virginia: Stylus.

Pastore, R. S. (2003). Dale’s cone of experience. Principles of teaching. Bloomsburg University: Bloomsburg, PA

Wlodkowski, R. J. (2008). Enhancing adult motivation to learn: A comprehensive guide for teaching all adults (3rd ed.) New Jersey: Jossey-Bass.

Wlodkowski, R. J., \& Ginsberg, M. B. (2003). Diversity and motivation: Culturally responsive teaching. New Jersey: Jossey-Bass.

\section{Athabasca University $\mathbf{A}$}

